TITLE:

\title{
Collaborative Action Development for Community Disaster Reduction by Utilizing the Yonmenkaigi System Method
}

$\operatorname{AUTHOR}(\mathrm{S}):$

Na, Jong-il; Okada, Norio; Fang, Liping

\section{CITATION:}

Na, Jong-il ... [et al]. Collaborative Action Development for Community Disaster Reduction by Utilizing the Yonmenkaigi System Method. Proceedings of the 2009 IEEE International Conference on Systems, Man, and Cybernetics 2009: 1929-1934

\section{ISSUE DATE:}

2009-10

URL:

http://hdl.handle.net/2433/109798

\section{RIGHT:}

(c) 2009 IEEE. Personal use of this material is permitted. However, permission to reprint/republish this material for advertising or promotional purposes or for creating new collective works for resale or redistribution to servers or lists, or to reuse any copyrighted component of this work in other works must be obtained from the IEEE. 


\section{Collaborative Action Development for Community Disaster Reduction by Utilizing the Yonmenkaigi System Method}

\author{
Jong-il NA \\ Graduate School of Urban Management \\ Engineering \\ Kyoto University, Kyoto, Japan \\ njiworld@drs.dpri.kyoto-u.ac.jp
}

\author{
Norio OKADA \\ Disaster Prevention Research Institute \\ Kyoto University, Kyoto, Japan \\ n_okada@drs.dpri.kyoto-u.ac.jp
}

\author{
Liping FANG \\ Department of Mechanical and Industrial \\ Engineering \\ Ryerson University, Toronto, Canada \\ lfang@ryerson.ca
}

\begin{abstract}
The Yonmenkaigi system method is utilized for developing a collaborative action plan for disaster risk mitigation at the community level. A case study carried out in the Shuhachi community, City of Kyoto, Japan, demonstrates how residents who are interested in disaster reduction in a local community can collaboratively develop an implementable action plan for their community. The Yonmenkaigi system method has the following main steps: carrying out a SWOT analysis, completing a Yonmenkaigi Chart, debating between groups, and presenting the group action plan. Relationships of the debated action plan components are analyzed by using the Interpretive Structural Modeling (ISM) method. For the case study, the core action plan component which is the root to achieving the action plan is identified.
\end{abstract}

Keywords-action plan, disaster prevention, participatory workshop method, the Yonmenkaigi system method, Interpretive Structural Modeling (ISM)

\section{INTRODUCTION}

Valuable lessons have been learned from recent lowfrequency/high impact disasters such as the 1995 Great Hanshin Earthquake Disaster in Japan and other disasters around the world. One of the lessons is that local government may not be immediately able to set up local headquarters to organize and implement emergency and crisis management in order to engage in rescue and relief activities as quickly as possible [11]. Therefore, the enhancement of disaster coping capacity and preparedness at the community level is crucial. In the 2008 Disaster Prevention White Paper [3], the Government of Japan put the emphasis on the roles of local communities, community-self-reliance (kyojo in Japanese), as well as on selfreliance, household/individual (jijo).

In Japan, after the 1995 Great Hanshin Earthquake Disaster, participatory workshops for the improvement of local disaster reduction capacity have been initiated to provide disaster prevention education in communities. However, most current methods for participatory workshops for disaster reduction focus on the rescue and relief activities of post-disaster situations, rather than on the pre-disaster period or on mitigation and preventive measures [9]. The general objective of a participatory workshop is to provide a forum for residents to share risk awareness and to communicate with others. Risk awareness discussed in such workshops does not lead to action plans for risk mitigation and preparedness activities from the local community's point of view. Facilitators determine the disaster risks and the roles and responsibilities of the community members in the workshops. As a result, current workshop methods are unable to adequately reflect the view of local communities. A workshop facilitator considers a hypothetical situation rather than the local context. A detailed comparison of several workshop methods is reported by $\mathrm{Na}$ et al. [9].

In order to reduce disaster impact at the local community level, collaborative action is necessary. Risk awareness should lead to implementable actions to improve the capacity of a local community in disaster situations. Workshop methods can be used to develop more effective action plans at the community level that include collaborative decision-making techniques among residents for proactive disaster management. In particular, a workshop method, called the Yonmenkaigi system method, has been proposed to create collaborative action plans for improving disaster reduction capacity in communities [8][9]. The Yonmenkaigi system method was originally designed and used for collaborative action development for a small group in community-citizen vitalization initiatives called machizukuri in a mountainous municipality of Chizu Town, Tottori, Japan [12].

The Yonmenkaigi system method has two objectives. Firstly, knowledge that is linked to action is obtained from each participant. Secondly, a collaborative action plan at the local community level is developed so that participants are able to learn more than enhanced risk awareness and may develop communication among themselves. To improve disaster reduction activities in local communities, an important and necessary element is collaborative activities by residents.

In this paper, a Yonmenkaigi system workshop which was conducted for a Jishubosai-soshiki (Self-governed Community Association for Disaster Reduction) in the City of Kyoto, Japan, is used as a case study to demonstrate collaborative action development at the local community level. An action plan consisting of many action components is developed. Relationships of action plan components are analyzed using the Interpretive Structural Modeling (ISM) method. 


\section{YONMENKAIGI SYSTEM METHOD}

\section{A. Overview of the Yonmenkaigi System Method}

The primary objective of the Yonmenkaigi system method is to develop a collaborative action plan for a community in a workshop with a disaster risk context. In order to achieve the objective, the system method focuses on four broad aspects of management, public relations (PR) and information, soft logistics, and hard logistics. These four aspects (roles) are considered required issues for future action. The time dimension is also considered with each of these role sharing elements.

Participants of the Yonmenkaigi system method first collect information and knowledge from a community diagnosis exercise and then decide for themselves on the theme/goal of the action plan. Afterwards, the action plan to achieve their goal as well as a plan to implement the action plan are developed by participants. The basic characteristics of the Yonmenkaigi system method that has actually been practiced in neighborhood communities in Kyoto can be summarized as follows [9]:

- The goal is to collect the visions and hopes of residents for proactive disaster reduction planning.

- The main application domain is disaster mitigation and prevention.

- As representatives of residents, members of Selfgoverned Community Association for Disaster Reduction participate in a workshop. Typically, one team of 8 to 16 participants is divided into four groups of two to four people each.

- The facilitator, who is a specialist, suggests guidelines and participants determine the theme and scenarios based on the local context.

- The main outcome is an action plan for disaster reduction for the local community.

A Yonmenkaigi system workshop provides a platform for face to face communication for participants to become aware of the concerns of others, to discuss the current state of their community and to collaboratively develop an implementable action plan. In this workshop method, the process of making collaborative action plans is systematically developed. Other workshop methods lack this type of system [9]. The emphasis of the Yonmenkaigi system method is on disaster mitigation and prevention rather than on post-disaster situations. In the Yonmenkaigi system method, participants serve the roles of both planners and executors as subjects of the action plans.

\section{B. The Process of the Yonmenkaigi System Method}

The process of the Yonmenkaigi system method consists of four main steps: carrying out a SWOT analysis, completing the Yonmenkaigi Chart, debating, and presenting the action plan chart, as shown in Fig. 1. Carrying out a SWOT analysis [5] constitutes the first step of the process. The SWOT analysis provides the participants with an opportunity to share their ideas and views about the current state of the community, which leads to a holistic and detailed view of risks faced by the community and future actions. In the SWOT analysis, four types of color cards, corresponding to the four SWOT categories of Strengths, Weaknesses, Opportunities, Threats, are used to express participants' views.

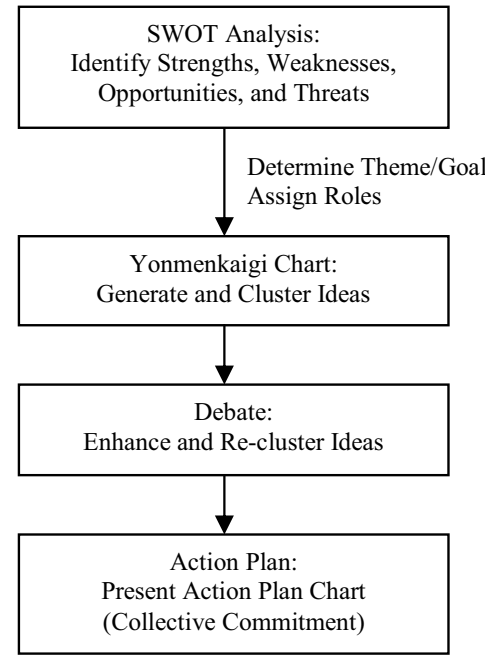

Figure 1. Process of the Yonmenkaigi system method.

Taking into account the current conditions of the community identified during the SWOT analysis, participants then determine the theme/goal of the workshop. Afterwards, the participants are divided into four groups. Each of the four groups is assigned one of the four roles of management, public relations (PR) and information, soft logistics, and hard logistics. Once the group/role assignment is complete, participants start to express their action components and views in accordance with their assigned role by utilizing color cards in a specially designed chart called Yonmenkaigi Chart, as shown in Fig. 2. By constructing a Yonmenkaigi Chart, participants set out the vision and actions for the four groups/roles. The action components for each of the roles are grouped according to one of the time frames: within 3 months, within 6 months, within 1 year, and beyond 1 year. Participants discuss within their respective groups and plan the actions of their assigned role. The implementable collaborative action plan is a coordinated combination of the actions developed by the four roles/groups.

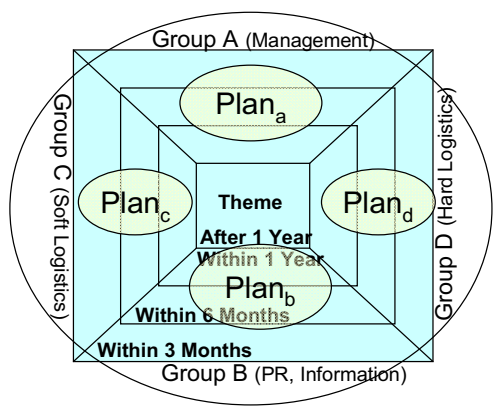

Figure 2. Typical patten of the Yonmenkaigi chart [9] 
Once each group completes the articulation of its action components, debating among groups is carried out to enhance the collaborative action plan. The Yonmenkaigi system method has two types of debates - general debate involving inter-group debate and inverse debate involving the exchange of the positions and roles of two groups facing each other across the Yonmenkaigi Chart as shown in Table I. Finally, participants develop an action plan chart for the future.

TABLE I. GENERAL AND INVERSE DEBATING IN THE YONMENKAIGI SYSTEM METHOD

\begin{tabular}{|l|l|l|}
\hline \multicolumn{1}{|c|}{ Role } & \multicolumn{1}{|c|}{ Management } & \multicolumn{1}{c|}{ PR \& Information } \\
\hline General Debate & Group A & Group B \\
\hline Inverse Debate & Group B & Group A \\
\hline Rules & $\bullet \quad$ Defend Own Group \\
& $\bullet \quad$ Criticize the Other Group \\
\hline
\end{tabular}

\section{THE SHUHACHI-BOSAIKAI CASE STUDY}

\section{A. Shuhachi-bosaikai}

The Shuhachi community is located in the Shuhachi elementary school area, Nakagyo Ward, Kyoto City, Japan. It is an urban residential area in the center of the City of Kyoto having 10,939 residents as of 2005 over an area of 1.055 square kilometers. It is further divided into 52 smaller community units (chonai/chonai-kai), which are neighborhood associations and are the smallest collective self-governing units in Japan [10].

There is a Jishubosai-soshiki (Self-governed Community Association for Disaster Reduction) in the Shuhachi community. The Jishubosai-soshiki has a headquarters (Shuhachi-bosaikai) and one or two representative members from each chonai-kai. The Shuhachi-bosaikai is a group organized by residents for the purpose of disaster prevention. It organizes and implements self-motivated disaster prevention activities in the Shuhachi community. According to chonai-kai rules, representatives from the chonai-kai are changed every year or two. The Shuhachi-bosaikai has established a disaster prevention partnership with the local fire station in the Shuhachi community.

\section{B. The Shuhachi Yonmenkaigi Workshop}

The Shuhachi-bosaikai was interested in developing an action plan for the Safety and Security mapping of the Shuhachi community. Accordingly, the Shuhachi Yonmenkaigi workshop was conducted in the Shuhachi community on January 26, 2008. Eight people from the Shuhachi-bosaikai participated in the workshop which lasted for three and a half hours. The first author of this paper, who served as the facilitator, first introduced the rules and methods of the workshop to the participants. A questionnaire was designed in order to survey the level of understanding and awareness of the present situation in the local community. 65 people, including community residents and members of the Shuhachi-bosaikai, chonai-kai, and the local fire station, completed the questionnaire during the period of December 22, 2007, to January 8, 2008.

The results of the questionnaire were used to assist the participants in carrying out the SWOT analysis of the Shuhachi community. Through the SWOT analysis, the participants discovered that the Shuhachi community did not have a hazard map or a local community housing map. Therefore, the participants decided that the theme/goal of the workshop was to produce security and safety maps of the community and selected a one year period as the realistic time frame for achieving the goal. From the eight participants, four groups of two each were formed to play the roles of management, PR \& information, soft logistics, and hard logistics. The corresponding responsibilities of the four groups are management, communication, human resources, and physical resources, to achieve the theme/goal of the workshop as determined earlier. The time frames of actions considered by the Shuhachi-bosaikai Yonmenkaigi workshop are shown in Fig. 2 as within 3 months, within 6 months, within 1 year, and beyond 1 year.

During the Yonmenkaigi workshop, some of the issues discussed were:

- It was first decided that a hazard map of the Shuhachi community is needed.

- The Shuhachi-bosaikai should explain to the Shuhachi community the importance of having a hazard map and should request the help of representative members of chonai-kai.

- The Shuhachi-bosaikai is aware that it does not have sufficient resources to produce a hazard map by itself.

- The Shuhachi-bosaikai should ask other community organizations to take collaborative actions and to implement this project together at the community level.

- Through this process of brainstorming for scenario generation, the Shuhachi-bosaikai recognized the need for collaborative action for disaster reduction in the Shuhachi community.

\section{Collaborative Action Development during Debate}

In the Yonmenkaigi workshop method, cards are used by participants to express and exchange views and ideas. During the debate stage, the multi-level knowledge development process of the debating practice is reflected through card movements. Several basic rules for the movement of cards have been developed as follows [9]:

- Add a new card: a new action component has been identified. During the Shuhachi Yonmenkaigi workshop, for example, the group playing the role of management added a new action component card of collecting cases to show the importance of a hazard map. It was noted that the Shuhachi-bosaikai should collect cases to show the importance of having a hazard map so that other members can appreciate its usefulness.

- Move a card: the action component is more suitable or preferable in the moved-to group rather than in the original group.

- Delete a card: the action component is no longer needed or desirable.

- Renewal of a card: the action component is enhanced to reduce the weakness of the group

- Arrange cards: cards are arranged and grouped by considering the time frames of the action components. 
- Collaboration shifts of cards: the action components require more than one group to implement. During the Shuhachi Yonmenkaigi workshop, the action component card of developing the contents required in the hazard map, the card of recruiting volunteers in the Shuhachi community to create the hazard map, and seven other cards were moved to the border areas between the management group and the other groups. It was noted by participants that the Shuhachi-bosaikai needs to work together with other groups to implement these action components because its own capacities are limited.

In the Shuhachi Yonmenkaigi Workshop, as shown in Table II, four groups of management, PR \& information, soft logistics, and hard logistics created 18, 18, 18, and 24 action component cards, respectively, for a total of 78 action cards in the Yonmenkaigi Chart before debating. After debating, the numbers of action component cards increased to 21, 27, 21, and 30 , respectively, for a total of 99 . In Table II, the cards of collaboration (shifts) are counted in each of the collaborating groups.

TABLE II. ACtion Plan COMPONENTS BEFORE AND AFTER Debate [9]

\begin{tabular}{|l|l|l|l|l|}
\hline & $\begin{array}{c}\text { Management } \\
(\mathrm{M})\end{array}$ & \multicolumn{1}{c|}{$\begin{array}{c}\text { PR \& } \\
\text { Information } \\
(\mathrm{I})\end{array}$} & $\begin{array}{c}\text { Soft } \\
\text { Logistics } \\
(\mathrm{S})\end{array}$ & $\begin{array}{c}\text { Hard } \\
\text { Logistics } \\
(\mathrm{H})\end{array}$ \\
\hline $\begin{array}{l}\text { Before } \\
\text { debate }\end{array}$ & 18 & 18 & 18 & 24 \\
\hline \multicolumn{5}{|c|}{} \\
\hline Arrange & 1 & \multicolumn{5}{|c|}{} \\
\hline Add & 2 & 0 & 1 & 4 \\
\hline Move & 1 & 3 & 0 & 3 \\
\hline Collaborate & 9 & 1 & 0 & 0 \\
\hline No change & 8 & 8 & 4 & 5 \\
\hline Total & 21 & 15 & 21 & 18 \\
\hline
\end{tabular}

\section{RELATIONSHIPS OF ACTION PLAN COMPONENTS}

An action plan developed by participants in a Yonmenkaigi workshop usually has many components. It is important to examine relationships among components of an action plan, in particular, precedence relationships among components. Participants may instinctively assess such tasks in a rough manner. In this section, the Interpretive Structural Modeling (ISM) method [13][14] is used to methodologically elaborate on the study of relationships of action plan components.

\section{A. Interpretive Structural Modeling (ISM) Method}

The ISM method is one of the techniques which analyze complex structures qualitatively from the field of social systems engineering [13][14]. The ISM method has been applied a variety of problems including higher education program planning [4], vendor selection [7], group decision making [1], alliance partner selection [6], and identification and quantification of interactive risks [2].

The ISM method is used to provide fundamental understanding of the structure of complex systems. Generally, complex systems can be divided into several components. In the ISM method, the interrelationships between components are modeled using a relationship matrix. Based on the relationship matrix, a structural graph can be constructed and the relationships of components are illustrated.

\section{B. Application of the ISM Method in the Yonmenkaigi System}

The primary objective of carrying out an ISM analysis in the Yonmenkaigi system method is to identify the core action components of a collaborative action plan by revealing the relationships of action components. The general process of an ISM analysis is shown in Fig. 3. Given a list of action components, the relationship matrix can be created. By using an ISM application program, the structural graph can be drawn and the results can be analyzed.

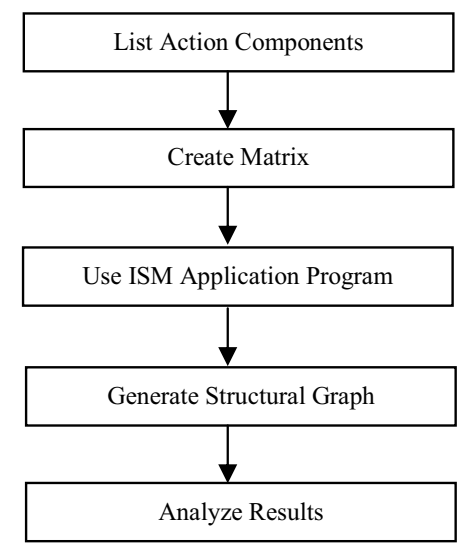

Figure 3. General process of an ISM analysis.

As shown in Table II, the Shuhachi Yonmenkaigi system workshop generates 21 action components for the group playing the role of management. These 21 action components are given in Table III. Action component numbers 4, 9, 10, 14, $15,16,17,18$, and 19 in Table III are categorized as collaborative action components.

The relationships of these 21 action components are analyzed by using the ISM Cognitive-networks Applied System, which is available from an open source (http://web.sfc.keio.ac.jp/ suzuryo/study/ism/src/demo/index.h tml.) ISM concepts and techniques make it easier to clarify the order of implementation of the action components to be carried out by the management group of the Shuhachi Yonmenkaigi system workshop. Use of the ISM method improves understanding of the action components of a group. An ISM analysis can also define the structure of the action plan components in the Yonmenkaigi Chart.

The action components are divided into four time frames in the Yonmenkaigi chart as the accomplishment periods in which action components are achieved. Within the management group's 21 action components, for example, numbers 1 to 9 are the action components required to be carried out within 3 months. Numbers 10 to 16 are the action components to be implemented within 6 months. Numbers 17 to 19 are the action components to be completed within 1 year. Numbers 20 and 21 are the action components to be carried out beyond 1 year. 
However, a time frame in the Yonmenkaigi chart does not have the ability to clearly distinguish the order of implementation of the action components in that time frame. Within each time frame, the action component cards are arranged according to the timed order of implementation from the left to right direction

TABLE III . ACTION COMPONENTS OF THE MANAGEMENT GROUP (SHUHACHI-BOSAIKAI)

\begin{tabular}{|c|c|}
\hline No. & $\begin{array}{l}\text { The Action Components of the Management Group } \\
\text { (Shuhachi-bosaikai) in the Shuhachi Yonmenkaigi System } \\
\text { Workshop }\end{array}$ \\
\hline 1 & Thinking about the usefulness of a hazard map \\
\hline 2 & Collecting cases showing importance of a hazard map \\
\hline 3 & Opening the Shuhachi-bosaikai meetings \\
\hline 4 & $\begin{array}{l}\text { Creating education flip boards describing the need for a } \\
\text { hazard map }\end{array}$ \\
\hline 5 & $\begin{array}{l}\text { Asking the questionnaires of the new hazard map to members } \\
\text { of chonai-kai }\end{array}$ \\
\hline 6 & $\begin{array}{l}\text { Deciding who will be the main organization to create the } \\
\text { hazard map }\end{array}$ \\
\hline 7 & Asking representative members of chonai-kai for help \\
\hline 8 & $\begin{array}{l}\text { Considering dissenting opinions of creating a hazard map in } \\
\text { the Shuhachi community }\end{array}$ \\
\hline 9 & Reviewing hazard maps of other local communities \\
\hline 10 & Considering the contents of the proposed hazard map \\
\hline 11 & $\begin{array}{l}\text { Discussing the feasibility of making a hazard map of every } \\
\text { chonai-kai }\end{array}$ \\
\hline 12 & $\begin{array}{l}\text { Determining the distribution area of the hazard map in the } \\
\text { Shuhachi community }\end{array}$ \\
\hline 13 & Recruiting new members for the Shuhachi-bosaikai \\
\hline 14 & Meeting with the Shuhachi schools about the hazard map \\
\hline 15 & Requesting cooperation from the Shuhachi community \\
\hline 16 & Determining whether fund-raising campaigns are necessary \\
\hline 17 & $\begin{array}{l}\text { Marking available fire extinguishers in the Shuhachi } \\
\text { community }\end{array}$ \\
\hline 18 & $\begin{array}{l}\text { Recruiting volunteers for creating the hazard map in Shuhachi } \\
\text { community }\end{array}$ \\
\hline 19 & Opening the Shuhachi-bosaikai and chonai-kai meetings \\
\hline 20 & Checking the contents of the hazard map before finalizing \\
\hline 21 & Distributing the hazard map in the Shuhachi community \\
\hline
\end{tabular}

For the action components given in Table III, the precedence relationship matrix of the components is shown in Fig. 4, in which

- element $A_{i j}$ is defined as follows: $A_{i j}=1$ if action component $j$ is a precedent action component for $i$ and $A_{i j}=$ 0 otherwise, as well as

- $\quad i, j=1,2, \ldots, 21$ are the action components given in Table III.

Identification of the precedence relationship matrix of the action components was performed by the first author who acted in the role of facilitator in the Shuhachi Yonmenkaigi workshop. For example, $A_{2 I}=1$ in Fig. 4 means that action component number 1 is a precedent action component for 2 .

\section{Results and Discussion}

After the debate phase, the time frames in the Yonmenkaigi Chart were changed from three time frames to four, which added "Beyond 1 year". Given the matrix in Fig. 4, by using the ISM Cognitive-networks Applied System, the structural graph is obtained, as shown in Fig. 5. As can be seen in Fig. 5, the 21 action components were divided into 8 levels, within 4 time frames.

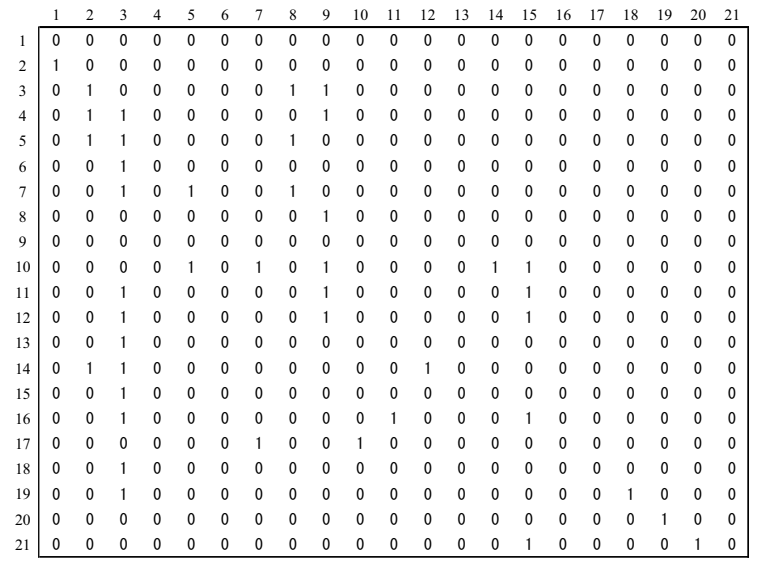

Figure 4. Precedence relationship matrix of action components for the management group (Shuhachi-bosaikai).

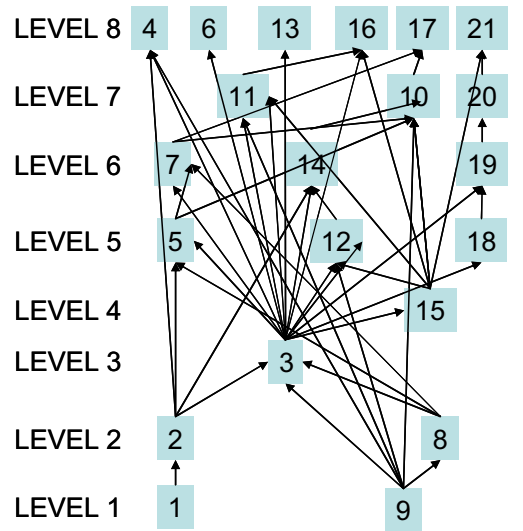

Figure 5. Structural graph of action components for the management group (Shuhachi-bosaikai)

The order of implementation for the action components of the management group (Shuhachi-bosaikai) are all connected from Numbers 1 to 21 . Each action component is linked to various other components, ranging from 1 to 15 . In particular, the Number 3 action component card (opening the Shuhachibosaikai meetings) is linked with the most other components (15 components).

The structure of the action components in the time frame of "within 3 months" is discussed now. In the time frame of "within 3 months," essentially, there are three paths of action 
plan components, which are: Numbers $[(1 \rightarrow 2)$ or $(9 \rightarrow 8)] \rightarrow 3$ $\rightarrow 4$, Numbers $[(1 \rightarrow 2)$ or $(9 \rightarrow 8)] \rightarrow 3 \rightarrow 6$, and Numbers [(1 $\rightarrow 2)$ or $(9 \rightarrow 8)] \rightarrow 3 \rightarrow 5 \rightarrow 7$ by the order of implementation as shown in Fig. 6 . In both $(1 \rightarrow 2)$ and $(9 \rightarrow 8)$, the Shuhachibosaikai considers the usefulness and importance of a hazard map by taking into account examples from other communities and dissenting opinions in the Shuhachi community. The three paths end at action component numbers 4, 6, and 7, respectively. The first action plan component path that ends at Number 4 shows that the Shuhachi-bosaikai management group creates education flip boards describing the need for a hazard map after collecting cases showing importance of a hazard map. The second action plan component path that terminates at Number 6 demonstrates that the Shuhachibosaikai recognizes the need for selecting the main organization in the community for making the hazard map. The third action plan component path that ends at Number 7 determines the contents of the hazard map with collaborative actions in the Shuhachi community as the path is connected to Number 10 (considering the contents of the proposed hazard map).

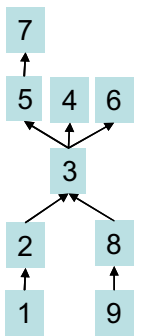

Figure 6. The order of implementation of action components for the management group (Shuhachi-bosaikai) within 3 months.

All paths of action plan components contain the Number 3 card (opening the Shuhachi-bosaikai meetings) as a common action component. The Number 3 action component card has a close relationship to many other action components. This means that to perform this action component is important in order to effectively carry out the action plan of the management group (Shuhachi-bosaikai). According to this, the management group should determine the strategic choice and focus its activities for making a hazard map on the action component of "opening the Shuhachi-bosaikai meetings," which then becomes the core action component of the action plan. Therefore, through the ISM analysis, the core action component (Number 3) has been identified.

\section{CONCLUSIONS}

The Yonmenkaigi system method has been used for making a collaborative action plan for disaster risk mitigation at the community level. Members of the Self-governed Community Association for Disaster Reduction (Jishubosai-soshiki) in the Shuhachi community, Nakagyo Ward, City of Kyoto, Japan, developed an implementable collaborative action plan for their community through a Yonmenkaigi system workshop. The Yonmenkaigi system method provides a means to go from risk awareness to collaborative action plan creation for disaster reduction. Moreover, the Yonmenkaigi system method furnishes a useful tool for enhancing local communities' disaster coping capacity and preparedness. Furthermore, following a disaster, the Yonmenkaigi system method can also be utilized as an assessment and feedback tool not only to review the effectiveness of a plan but also to update and revise existing plans for disaster reduction.

The Interpretive Structural Modeling (ISM) method has been used to methodologically elaborate the action plan outcomes of a Yonmenkaigi system workshop. It helps study relationships of action plan components developed by participants in a Yonmenkaigi system workshop. A structural graph of action plan components is drawn. Furthermore, the core action component that has many links with other action components is identified which is the root to achieving the action plan.

\section{REFERENCES}

[1] R. Bolanos, E. Fontela, A. Nenclares, and P. Pastor, "Using interpretive structural modelling in strategic decision-making groups," Management Decision, Vol. 43, No. 6, pp. 877-895, 2005.

[2] R. Gorvett and N. Liu, "Using interpretive structural modeling to identify and quantify interactive risks," The 2007 ASTIN (Actuarial Studies in Non-Life Insurance) Colloquium, Orlando, FL, USA, June 19-22, 2007

[3] Government of Japan, The 2008 Disaster Prevention White Paper, Tokyo, Japan , 2008 (in Japanese)

[4] RW. Hawthorne and A.P. Sage, "On applications of interpretive structural modeling to higher education program planning," SocioEconomic Planning Sciences, Vol. 9, pp. 31-43, 1975.

[5] T. Hill and R. Westbrook, "SWOT analysis: it's time for a product recall," Long Range Planning, Vol. 30, No.1, pp. 46-52, 1997.

[6] N. Ma and X. Li, "University-industry alliance partner selection method based on ISM and ANP," Proceedings of the International Conference on Management Science and Engineering, Aveiro, Portugal, October 57, 2006, pp. 981-985.

[7] A. Mandal and S.G. Deshmukh, "Vendor selection using interpretive structural modelling (ISM)," International Journal of Operations and Production Management, Vol. 14, No. 6, pp. 52-59, 1994.

[8] J. Na, N. Okada, and L. Fang, "A collaborative action development approach to improving local community disaster prevention planning," Book of Extended Abstracts, 27th Annual Conference of the Japan Society for Natural Disaster Science, Fukuoka, Japan, September 25-26, 2008, pp. 95-96 (in Japanese).

[9] J. Na, N. Okada, and L. Fang, "A collaborative action development approach to improving community disaster reduction by the Yonmenkaigi system method," Working Paper, Disaster Prevention Research Institute, Kyoto University, Japan, 2009.

[10] G. Nitschke, "Street or neighbourhood, street-perspectives on Asia," Kyoto Journal, September 2003, 55.

[11] N. Okada, "Urban diagnosis and integrated disaster risk management," Journal of Natural Disaster Science, Vol. 26, No. 2, pp. 49-54, 2004

[12] N. Okada, and A. Teratani, "The Yonmenkaigi system," RIIM Report No. 5, Research Institute of Infrastructure Management, Japan Civil engineering Consultants Association (JCCA), 2005, pp. 35-38 (in Japanese).

[13] J.N. Warfield, "Binary matrices in system modeling," IEEE Transactions on Systems, Man, and Cybernetics, Vol. 3, No. 5, pp. 441-449, 1973.

[14] J.N. Warfield, Societal Systems: Planning, Policy, and Complexity.New York: Wiley, 1976. 